\title{
Climate change, physical activity and sport: a systematic review
}

\author{
Paquito Bernard ${ }^{1,2}$, Guillaume Chevance ${ }^{3}$, Celia Kingsbury ${ }^{1,2}$, Aurélie Baillot ${ }^{4,5}$, Ahmed-Jérôme \\ Romain $^{2,6}$, Virginie Molinier ${ }^{7}$, Tegwen Gadais ${ }^{1}$, Kelsey N. Dancause ${ }^{1}$ \\ ${ }^{1}$ Department of Physical Activity Sciences, Université du Québec à Montréal, Montréal, Québec, \\ Canada \\ ${ }^{2}$ Research Center, Montreal University Institute of Mental Health, Montréal, Quebec, Canada \\ ${ }^{3}$ Center for Wireless \& Population Health Systems, Department of Family Medicine and Public Health, \\ UC San Diego, San Diego, CA 92093 USA \\ ${ }^{4}$ Department of Nursing at the Université du Québec en Outaouais, Canada \\ ${ }^{5}$ Institut du Savoir Montfort-Recherche, Ottawa, Canada \\ ${ }^{6}$ École de kinésiologie et des sciences de l'activité physique, Faculté de Médecine, Université de \\ Montréal, Montréal, Québec, Canada \\ ${ }^{7}$ Les Cliniques du Souffle, Groupe 5 Santé, France
}

Correspondence concerning this article should be addressed to:

Paquito Bernard, PhD, Université du Québec à Montréal, Montréal, Canada

Faculté des sciences, UQÀM, Complexe des Sciences, Pavillon des sciences biologiques (SB), Local: SB-4445, 141, Avenue du Président Kennedy, Montréal, Québec, Canada, H2X 1Y4

bernard.paquito@uqam.ca

@PaquitoBernard

Bernard P et al. (2021). Climate change, physical activity and sport: a systematic review. Sports Medicine, https://doi.org/10.1007/s40279$\underline{021-01439-4}$ 


\section{Abstract}

\section{Background}

Climate change impacts are associated with dramatic consequences for human health and threaten physical activity (PA) behaviors.

\section{Objective}

The aims of this systematic review were to present the potential bidirectional associations between climate change impacts and PA behaviors in humans and to propose a synthesis of the literature through a conceptual model of climate change and PA.

\section{Methods}

Studies published before October 2020, were identified through database searches in Pubmed, PsycArticles, CINAHL, SportDiscus, GreenFILE, GeoRef, Scopus, JSTOR and Transportation Research Information Services. Studies examining the associations between PA domains and climate change (e.g., natural disasters, air pollution, carbon footprint) were included.

\section{Results}

A narrative synthesis was performed and the 74 identified articles were classified into 6 topics: air pollution and PA, extreme weather conditions and PA, greenhouse gas emissions and PA, carbon footprint among sport participants, natural disasters and PA and the future of PA and sport practices in a changing world. Then, a conceptual model was proposed to identify the multidimensional associations between climate change and PA as well as sport practices. Results indicated a consistent negative effect of air pollution, extreme temperatures and natural disasters on PA levels. This PA reduction is more severe in adults with chronic diseases, higher body mass index and the elderly. Sport and PA communities can play an important mitigating role in post-natural disaster contexts. However, transport related to sport practices is also a source of greenhouse gas emissions.

\section{Conclusion}

Climate change impacts affect PA at a worldwide scale. PA is observed to play both a mitigation and an amplification role in climate changes.

\section{Trial Registration Number}

PROSPERO CRD42019128314

\section{Key points}

- Air pollution, extreme weather events and natural disasters are associated with decreased physical activity in adults

- Physical activity communities play an important role in resilience and recovery following natural disasters

- Regarding greenhouse gas emission, physical activity is part of the problem and part of the solution 


\section{Declarations}

\section{Data availability statement}

Research protocol and data files (.bib) are available in the following OSF account: https://osf.io/z2us6.

\section{Authors' contributions}

PB conceived the study. Data collection and extraction were performed by PB, CK and GC. All authors contributed to refinement of the study protocol, and edited, revised and approved the final version of the manuscript.

\section{Compliance with Ethical Standards}

\section{Funding}

This research received no specific grant from any funding agency. PB is supported by the Université du Québec à Montréal, Institut Universitaire de Santé Mentale de Montréal and by a salary award from the Fonds de recherche du Québec - Santé. KD and AB hold a Chercheur-Boursier Junior 1 FRQS scholarship.

\section{Conflict of Interest}

Paquito Bernard, Guillaume Chevance, Celia Kingsbury, Aurélie Baillot, Ahmed-Jérôme Romain, Virginie Molinier, Tegwen Gadais and Kelsey Dancause declare that they have no conflicts of interest relevant to the content of this review.

\section{Acknowledgments:}

The authors would like to thank Philippe Squarzoni, Pablo Servigne, Jean-Marc Jancovici, Philippe Bihouix, and members of Thinkerview for their seminal work 


\section{Introduction}

The global population is living in a new geological epoch, the Anthropocene, which is characterized by major biophysical changes due to a human energetic footprint surpassing ecosystem thresholds [1,2]. The Anthropocene epoch is marked by rapid, exponential, and unsustainable growth in human population size, gross domestic product per capita, energy and water use, transportation and telecommunications, land loss, and ocean acidification since the 1950s [2]. According to more than 15,000 scientists from 184 countries, failing to curb these trends in the next two decades might lead to irreversible modifications for the earth's ecosystems and, ultimately, to conditions that would be inhospitable to current human societies and other contemporary species [3]. Among all anthrogenic changes, climate change is the one that is directly associated with human conditions. Authors of the United Nations' Intergovernmental Panel on Climate Change (IPCC) stressed the systemic and possible irreversible effects of climate change on human health, economy, communities and cultures [4].

The most severe indicators of climate change are global average warming, sea level rise and higher occurrence and severity of natural disasters (e.g. heat waves, drought and intense precipitation) $[5,6]$. These climate change-related outcomes are associated with dramatic consequences for human health and health systems, threatening populations especially in lowincome countries [7-10]. These effects occur through different pathways, such as increasing prevalence of heat-related illnesses [11] and illnesses caused by poor air quality [12], malnutrition from reduced food quality and security [13], an increasing burden of vector-borne diseases [9], violence related to climateinduced population displacement [14], and mental health issues related to more frequent extreme events and natural disasters [15]. Beyond these healthrelated outcomes, two recent systematic reviews have reported that climate change might also impact individuals' health behaviors, specifically sleep and eating behaviors [7,9]. For instance, poor air quality or repeated heat waves were associated with higher risk of insomnia. To our knowledge, no systematic review has yet been conducted regarding the association between physical activity behaviors, including active transport, recreational and sports activities, and climate change.

Existing research reveals complex, sometimes bi-directional, relationships between climate change and physical activity behaviors and sport practices $[16,17]$. Some studies have highlighted that in temperate climate regions, climate change (e.g., increase in temperatures) might positively impact physical activity behaviors (e.g., active travel) [17]. Conversely, climate change impacts such as heat waves and natural disasters are related to lower physical activity participation, decreased sport participation and limited sport performance in subtropical regions $[18,19]$. On the other hand, some researchers have argued that physical activity behaviors could play a major role in adaptation and mitigation strategies [20]. For instance, active travel has been associated with decreases in air pollution and $\mathrm{CO}_{2}$ emissions in some situations [21,22]. Physical activity organizations could also play a role in population resilience and recovery after natural disasters [23].

Two previous narrative reviews have examined associations between physical activity and climate change outcomes. A first review in 2003 highlighted that climate change impacts were related to lower physical activity participation in children and decreased sport participation during heat waves [24]. Recently, a second review concluded that the average level of physical activity was negatively affected during extreme heat episodes, particularly in adults with chronic diseases [25]. These previous reviews have focused mainly on the consequences of heat waves, and to date, there is no exhaustive review of the complex relationships between physical activity and range of other climate change impacts noted by the IPCC [4], such as air pollution or natural disasters. Previous reviews have also only focused on the effects of climate change on physical activity, without acknowledging the potential opposite role of physical activity on climate change (e.g., decreases in air pollution with active transport). Human activities (particularly burning fossil fuels) have caused extreme increases of atmospheric greenhouse gas concentrations, resulting in increases in surface air temperatures and subsurface ocean temperatures [26]. The impact of human activities on climate is generally operationalized in terms of the carbon footprint, i.e., the total amount of greenhouse gas emissions caused by an organization, event, product or person expressed in units of carbon dioxide equivalent [27]. Different physical activity and sport behaviors might have different impacts - including both positive and negative impacts - on the carbon footprint.

Due to the complexity of the climate change literature, an exhaustive review of the relationships between climate change and different physical activity behaviors and sport practices is needed. Hence, the purposes of this systematic review were to: 1) present the potential bidirectional associations between climate change impacts and physical activity behaviors in human and 2) propose the first synthesis 
of the literature through a conceptual model of climate

\section{Method}

Methods for collecting and summarizing data met the standards of the Preferred Reporting Items for Systematic Reviews and Meta-Analyses guidelines [28]. The study protocol was registered in PROSPERO (CRD42019128314). The study protocol was uploaded on the Open Science Framework (OSF) prior to data collection and analyses. All study materials are available on Open Science Framework) (https://osf.io/sbmni).

\subsection{Inclusion criteria}

Studies were included in the systematic review if they met the following criteria: 1) human participants, 2) peer-reviewed publications, 3) study designs: observational, interventional, conceptual, systematic review, and scenario-based models and computerized simulations, 4) published in French or English, 5) examining the associations between outcomes related to physical activity (i.e., sport practices [from leisure to elite practices], active travel, household or occupational physical activity, levels of physical activity and physical inactivity), and climate change impacts highlighted in the IPCC 2014 report [26] (i.e., extreme weather conditions, biodiversity damage or loss, water or snow quantity, air pollution concentration, sea level rise, development of vector born disease and climate related disasters: floods, bushfires, wildfires, tsunamis, storms, or direct and indirect carbon footprint (i.e., tons $\left(\mathrm{CO}_{2}\right.$-equivalent) of direct or indirect greenhouse gas emissions)). If a systematic review was found, we included it in the current review as well as articles published after its publication.

\subsection{Exclusion criteria}

Due to our focus on physical activity behaviors, studies examining pro-environmental behaviors in athletes or sport spectators (e.g., recycling behaviors among football fans), energy consumption or emissions of sport events (e.g., $\mathrm{CO}_{2}$ emissions of spectators' transportation in sporting events, water consumption during Olympic Games) or sport material (e.g., carbon footprint of surfboard production) have been excluded. Similarly, experimental physiology studies have not been included. Studies focusing on the association between physical activity and nuclear accidents, avalanches or earthquakes were excluded because their associations with climate change are not clearly established [29]. Books, chapters, or case reports were not included.

\subsection{Data sources and searches}

change and physical activity.

Studies were identified by searching Pubmed, PsycArticles, CINAHL, SportDiscus, GreenFILE, GeoRef, Scopus, JSTOR and Transportation Research Information Services electronic databases until October 2019 in English and French. An update was performed in October 2020. The search strategy was adapted for each database using its specific parameters. Details of the research strategies are provided in Electronic Supplementary Material Appendix S1. Additionally, relevant reviews were scanned [24,25,30-34] and the following academic journals were searched: Disaster Prevention and Management, Sport Management Review, Disaster Medicine and Public Health Preparedness. After duplicates were removed, titles and abstracts of all studies identified were examined independently (GC, $\mathrm{PB})$ to determine those meeting the selection criteria.

\subsection{Data synthesis}

A narrative synthesis [35] was carried out to synthesize the findings from included studies. This method was preferred because the range of study designs was expected to be very diverse. A preliminary synthesis was conducted by two researchers (PB, $C K)$ in the form of a thematic analysis. Results were then discussed and structured into themes by the research team (PB, CK, AJR, GC, $A B, V M, T G, K D)$. Finally, two researchers (PB, GC) developed a conceptual model to summarize results of the narrative synthesis within a graphic framework. Due to the very diverse nature of the included studies, a quality assessment of included articles was not performed. Indeed, quality assessment tools are available for specific study designs (e.g., NIH Quality Assessment Tool for Observational Cohort and CrossSectional Studies, Risk Of Bias In Non-randomised Studies - of Interventions tool, Briggs critical appraisal checklist for qualitative studies). The present review however, included studies with various research designs making difficult (or impossible) the utilization of such quality assessment tools.

\section{Results}

\subsection{Descriptive findings}

The initial electronic searches identified 922 references, of which 73 were duplicates. After reviewing titles and abstracts, 849 were excluded because they did not meet inclusion criteria. Assessment of full text was performed for 111 references. Twenty-two studies met the inclusion criteria. The complementary research strategies resulted in identification of 52 other articles. Thus, 74 academic articles were included in this review. Details of the literature search and selection process are 
provided in Figure 1. Included articles were published in journals from diverse academic disciplines, including sport, transportation research, tourism, disaster medicine, geography, environmental research and energy research. The format/design of included articles were: observational studies $(\mathrm{N}=31)$, experimental studies $(\mathrm{N}=9)$, scenario-based studies $(\mathrm{N}=25)$, systematic reviews $(\mathrm{N}=4)$ and conceptual studies $(\mathrm{N}=5)$. Figure 2 illustrates the countries in which empirical data reported in the articles or reviews were collected, or authors' locations for conceptual papers. The map was plotted using the $\mathrm{R}$ package rworldmap [36]. The US was the most highly represented country (29 articles, 39\%).

\subsection{Narrative synthesis}

Results were summarized across six key themes: 1) air pollution and physical activity, 2) extreme weather conditions and physical activity, 3) greenhouse gas emissions and physical activity, 4) carbon footprint among sport participants, 5) natural disasters and physical activity and 6) the future of physical activity and sport practices in a changing world. Finally, we developed a conceptual model summarizing the bidirectional associations between physical activity outcomes and climate change consequences integrating observations from all six themes.

\subsubsection{Theme 1: Air pollution and physical activity}

A total of 12 publications (8 observational studies, 3 scenario-based studies, 1 systematic review) regarding associations between air pollution and physical activity were identified and organized into three sub-categories: associations between objective air pollution indicators and physical activity $(\mathrm{N}=4)$, associations between air pollution alerts or pollution perceptions and physical activity $(\mathrm{N}=4)$, and the possible mitigation effects of physical activity on air pollution $(\mathrm{N}=1)$.

\subsubsection{Associations between air pollution and} physical activity

A systematic review and meta-analysis examined the associations between physical activity (self-reported and daily step counts) and air pollution [37]. Among the seven included studies (six from the US and one from the UK), six had a large sample ranging from 10,000 to 2 million participants. Results of the meta-analysis showed that for one unit $\left(\mu \mathrm{g} / \mathrm{m}^{3}\right)$ increase in ambient particulate matter 2.5 concentration $\left(\mathrm{PM}_{2.5}\right)$, the odds of physical inactivity increased by $1.1 \%$. Stronger associations were observed in adults with respiratory symptoms such as chronic obstructive pulmonary disease. No other environmental exposure (e.g., ground-level ozone levels) could be examined in the statistical analysis.
Laffan et al. [38] confirmed the negative crosssectional associations between leisure physical activity and ambient PM2.5 concentration in a sample of UK adults $(\mathrm{N}=4277$, period 2012 - 2015).

Longitudinal associations between air pollution (ambient $\mathrm{PM}_{2.5}$ concentration) and self-reported physical activity were examined over one academic year among a large sample $(\mathrm{N}>3000)$ of students in Beijing (China) [39]. A one standard deviation increase in ambient $\mathrm{PM}_{2.5}$ concentration was associated with a reduction of moderate to vigorous physical activity by an average of 32 weekly minutes across the study [39].

Another investigation including over 9,000 Beijing students examined longitudinal associations between four air pollution indicators (i.e., a subjective air quality index, $\mathrm{PM}_{2.5}, \mathrm{PM}_{10}$, and $\mathrm{NO}_{2}$ ) and sedentary behavior (i.e., sitting time assessed with one item from the International Physical Activity Questionnaire) [40]. A one standard deviation increase in air pollution concentration of those indicators (Air Quality Index, $\mathrm{PM}_{2.5}, \mathrm{PM}_{10}$, and $\mathrm{NO}_{2}$ ) was associated with an increase in weekly total hours of sedentary behavior by $7.35,6.24,6.80$, and 7.06 , respectively.

\subsubsection{Associations between air pollution} alerts or pollution perceptions and physical activity

A systematic review conducted by An et al. [37] indicated (i) a negative association between selfreported air pollution measures (i.e., self-perceived ambient air quality, air quality index and media alerts) and outdoor physical activity, as well as (ii) a positive association between these air pollution outcomes and time spent in leisure sedentary activities.

An increase in media air pollution alerts was associated with lower walking time in South Korea between 2008 and 2017, whereas walking time was not correlated with actual $\mathrm{PM}_{10}$ concentration [41]. Ozone alerts in a park in Atlanta (US) during the summer of 2005 were related with reduced park use by joggers and elderly walkers [42]. Similarly, Saberian et al. [43] used data from electronic pathside devices placed in 31 points across different cycle paths and parks in Sydney (Australia; May 2008 - September 2013) to examine the effects of air pollution alerts on cyclist behaviors. Air quality alerts were associated with a $15-35 \%$ decrease in bicycle use and this effect was more pronounced in parks. The authors also identified a possible "habituation effect": when alerts were issued on two successive days, the decrease in cyclist behaviors resulting from the alerts was slightly lower.

Ward and Beatty [44] coupled the American Time Use Survey (2003-2010) with air pollution alerts (using an air quality index provided by the US Environmental Protection Agency) to investigate how these alerts were associated with vigorous outdoor 
physical activities. During alert days, time spent in vigorous outdoor physical activities was reduced by $18 \%$ (i.e., 21 minutes). However, this association was mainly driven by a decrease for participants aged $>65$ years, whose time spent in vigorous outdoor physical activities decreased by $82 \%$ following pollution alerts. This association was not significant among non-elderly adults. Notably, air pollution alerts were not compensated by a transfer toward indoor physical activities.

\section{activity on air pollution}

3.2.1.3 Possible mitigation effects of physical

In a study of transport scenarios in Adelaide (Australia), Xia et al. [46] quantified the predicted $\mathrm{PM}_{2.5}$ concentration if $5 \%$ or $10 \%$ of passenger vehicles shifted to cycling in 2030. These scenarios were associated with a reduction of total traffic-related emissions by $8.5 \%$ and $8.6 \%$, respectively. The largest reduction occurred when increased public transport and cycling were combined ( $26 \%$ reduction).

Two transport scenarios in Sao Paulo (Brazil), increased car use versus active transport development, were compared to actual 2012 travel patterns (in which $58 \%$ of trips were by public transit, $24 \%$ by active transit, and $18 \%$ by car) [47]. The $\mathrm{PM}_{2.5}$ concentration was lower in the scenario based on active transport development or 2012 travel patterns compared to the increased car use scenario [47].

Another study quantified $\mathrm{PM}_{2.5}$ concentration in Barcelona (Spain) with scenarios assuming two possible reductions in car trips $(20 \%$ or $40 \%)$ and total or partial active transport mode shifts [48]. The estimated air pollution reduction ranged from $0.32 \%$ to $1.16 \%[48]$.

\subsubsection{Theme 2: Extreme weather conditions and physical activity}

A total of 12 studies were identified and are described below in two sections: real world investigations $(\mathrm{N}=5)$ and scenario-based studies $(\mathrm{N}=7)$.

\subsubsection{Empirical studies}

\subsection{Leisure physical activity}

Obradovich and Fowler [16] examined the relationships between monthly weather conditions (maximal temperature, heat index, precipitation and relative humidity) and monthly self-reported leisure physical activity accounting for participants' body mass index (BMI) and age in a cross-sectional cohort study, including a US representative sample of 1.9 million adults (period 2002-2012). Results showed that the probability of monthly physical activity participation increased up to $28-29^{\circ} \mathrm{C}$ but decreased after $36^{\circ} \mathrm{C}$, with a drastic decline after $40{ }^{\circ} \mathrm{C}$. The same patterns were noted between the monthly heat index and monthly participation in physical activity. The authors
Zhao et al. [45] explored the association between air pollution perceptions (i.e., hazy weather) and cycling behavior among 307 adults living in Beijing, China. Hazy weather perception was related to a reduction of cycling and walking travel by $68 \%$ and $64 \%$, respectively. Residents with lower income, less access to public transport, over 30 years of age, women, and those living in suburban areas were more likely to cycle during hazy weather days.

indicated that this association was mainly driven by temperature rather than humidity. Furthermore, a small significant linear association was observed between physical activity and precipitation. More than 20 consecutive days with precipitation was related to a $1 \%$ reduction in the probability of monthly participation in leisure physical activity. Stratified analyses suggested that people with obesity (BMI $\geq 30 \mathrm{~kg} . \mathrm{m}^{2}$ ) and elderly individuals ( $>65$ years) had higher probability of physical activity reduction after $40^{\circ} \mathrm{C}$ than normal weight or overweight adults and younger or middle-aged adults, respectively.

Consistent with these observations, 42 to $55 \%$ of older respondents with a chronic disease reported a drastic reduction of their physical activity during the 2005 heat wave episode in Montreal (Canada) [49].

\subsubsection{Active transport}

Heaney et al. [50] explored the shape of the association between temperature-related indicators (i.e., daily average ambient temperature, minimum and maximum temperature, heat index) and outdoor cycling (daily total hours ridden and daily average distance ridden) in a cross-sectional study [50]. Data on bike rides were collected in New York City between June 2013 and September 2017. Meteorological data were obtained from the National Center for Environmental Information. A linear increase between daily total hours or average distance ridden and all temperature indicators was found until a maximum temperature threshold of around $26-28^{\circ} \mathrm{C}$. Following this threshold, a drastic decrease in daily time or distance ridden was observed. The same patterns were found in analyses stratified for sex, and weekday versus weekend. A similar threshold was found in a study aggregating bike sharing data from 17 cities in North-America: the number and duration of trips decreased after $26^{\circ} \mathrm{C}$ [51].

Finally, Al-Mohannadi et al. [52] led a 2-year cohort study in a sample of 2,088 Qatar residents (Arabian Gulf region). The study assessed associations between 2-year changes in objectively assessed physical activity (i.e., step counts per day and aerobic steps per day) and climatic conditions (i.e., outdoor average temperature, humidity, cloud cover, rain/thunderstorms and WetBulb Globe Temperature, WBGT). Models showed that increased temperature and humidity, and higher WBGT, were 
associated with a decrease in the daily number of steps. In addition, a substantial decline in both step counts and aerobic step counts was found on days when WBGT $>28^{\circ} \mathrm{C}$.

\subsubsection{Scenario-based studies}

\subsection{Global physical activity}

Obradovich and Fowler [16] estimated the probable future impacts of climate change on physical activity. They explored geographic variations in physical activity in the US and the possible change of physical activity distribution throughout the year. They then estimated the monthly maximum temperatures for 2050 and 2099 based on 21 models representing a "business as usual" scenario (i.e., worst-case scenario with a $4^{\circ} \mathrm{C}$ increase in 2100 [known as the Representative Concentration Pathway (RCP) 8.5]) provided by the IPCC [26]. The findings suggested that increases in global temperatures induced by climate change could result in an increase in physical activity during cooler months by 2100 . However, severe physical activity reductions were observed for summer months between June and August. These forecasted associations between physical activity and temperature might be not homogeneous across the US. Southern areas may experience more severe and prolonged physical activity decreases.

Heaney et al. [50] estimated differences in bikeshare usage (annual total hours and distance ridden) in New York in response to projected temperatures between 2040-2069. They ran 21 climates models under two scenarios: stabilization of emissions and concentrations (around $2.4{ }^{\circ} \mathrm{C}$ increase in 2100 [RCP 4.5]) and the "business as usual" scenario (RCP 8.5). The average annual hours ridden increased by $2.6 \%$ and $3.1 \%$ in RCP 4.5 and RCP 8.5 , respectively. The annual projected distance also increased by $0.59 \%$ and $0.74 \%$. However, monthly analyses also suggested that the annual number of hours ridden between June and August would decline by 2.9 and $4.5 \%$ for the two scenarios.

Maloney and Forbes [18] modelled the ability of the human body to transfer heat to the environment under projected future meteorological conditions. They established the yearly number of days between 2001 and 2070 by which Perth (Australia) residents will become either hyperthermic (i.e., failed heat balance resulting in hyperthermia) or living in "dangerous days" (i.e., body temperature increase $>2.5^{\circ} \mathrm{C}$ in less than 2 hours) in the context of moderate or vigorous physical activities. The number of days per year that an acclimatized person experiences hyperthermia may increase from 13 to 58 for moderate physical activities and from 31 to 94 during vigorous physical activities. The number of "dangerous days" - that is, days in which heat stroke could precipitate in 2 hours - may shift from 5 to 39 days and 17 to 67 days per year for people undertaking moderate or vigorous physical activities. The authors highlighted that a warming of 4 ${ }^{\circ} \mathrm{C}$ to $6{ }^{\circ} \mathrm{C}$ expected in 2070 will have important negative consequences for leisure and occupational physical activities and will increase the risk of heat illness during these activities.

Grundstein et al. [53] examined the expected frequency of days that exceed the most extreme American College of Sport Medicine risk category $\left(>32.3{ }^{\circ} \mathrm{C}\right.$ WBGT in the US), when training and practice activities are considered to pose a serious health threat. They based their scenario on the A2 IPCC model, a high emission model for 2040 - 2070. Based on their models, annual frequency of days exceeding the ACSM risk threshold could be doubled from 15 to 30 days. However, an important spatial variation was reported. Thus, 25 - 60 days would exceed safety thresholds in an arc extending northward from Texas into south Dakota. In states that border the Gulf Coast, $>85$ days would have afternoon WBGT $>32.3^{\circ} \mathrm{C}$. The authors also suggested that spring and fall sports (e.g., soccer, football, baseball) would be affected by an expansion of the seasonal range for days exceeding safety thresholds [53].

\subsection{Active transport}

Saneinejad et al. [17] used simple climate change models (temperature increasing, precipitation increasing or decreasing) to investigate their impacts on transport mode choice in Toronto (Canada). Biking was the transport mode most positively improved by temperature increase, with an expected number of trips increasing from $3 \%$ to $17 \%$ depending on the magnitude of temperature increase. Walking was predicted to increase by only $2 \%$ in all temperature scenarios. Wadud et al. [54] modeled bicycle use in 2050 in London (UK), based on a high emission scenario designed in 2009 and cycle count data collected between 2008-2011. Projected average annual hourly bicycle flow was not significantly different in comparison with 2011 data. Rather, a projected increase in average annual hourly bicycle flows with increasing temperature was projected, but this "positive effect" is expected to be tempered by an increase in rainfall. Seasonal projections suggested an increase of $1.5 \%$ and $2.5 \%$ in bicycle flows during winter and summer, respectively, but a reduction of $2.0 \%$ and $0.1 \%$ during the spring and autumn. Bocker et al [55] explored the impact of weather conditions in 2050 on choices of mode of travel and distances in the Dutch metropolitan Ranstad region (Netherlands). They selected seasons from the past as representative of 2050 climate. Results suggested that cycling may be a more frequently chosen travel mode in annual averages, with pronounced increases in winter and spring. Based on the 2016 American Time Use Survey and average median temperature and precipitation projection for 2060 in the US, Chan et al. 
[51] modelled the number of hours spent cycling for leisure purposes. The authors found that global increase of temperatures could induce large positive changes in leisure cycling.

Finally, Karner et al. [56] examined demographic and spatial disparities in terms of active travel during extreme heat episodes in San Francisco (US). They combined travel activity and urban meteorological data. Findings showed that socially disadvantaged residents (i.e., people with low income and zero-vehicle households) used disproportionately more non-motorized transportation during extreme heat episodes, resulting in potential health issues for this population.

\subsubsection{Theme 3: Greenhouse gas emissions and physical activity}

Thirteen studies examined associations between physical activity and greenhouse gas emissions. These studies were classified according to their designs: experimental $(N=5)$, observational $(N=2)$ and scenario-based $(\mathrm{N}=6)$.

\subsubsection{Experimental studies}

In a systematic review, Shaw et al. [21] investigated the "co-benefits" of car use decrease interventions in terms of active transport and $\mathrm{CO}_{2}$ emissions. Based on 22 studies, the authors suggested that interventions resulted in a modest increase in walking and cycling, while heterogeneous findings about $\mathrm{CO}_{2}$ emissions reduction were noted (from 104 to 20,000 tons eliminated over 6-month). They highlighted that methodological quality of included studies was poor, particularly for $\mathrm{CO}_{2}$ emissions quantification (i.e., based only on vehicle kilometers travelled).

Three more recent investigations confirmed the modest effect of interventions targeting active travel on $\mathrm{CO}_{2}$ emissions. First, a quasi-experimental study examined gas emissions during a community intervention that resulted in a $30 \%$ increase in the proportion of active transport trips in two cities with more than 70,000 residents in New Zealand (Hastings and New Plymouth) $[57,58]$. The intervention targeted walking and cycling infrastructure development (i.e., $30 \mathrm{~km}$ of arterial paths, $12 \mathrm{~km}$ of off-road facilities, 20 $\mathrm{km}$ of cycle lanes) coupled with health behavior change promotion efforts (i.e., media campaigns and cycle-training sessions in school). Two other cities (Whanganui and Masterton) acted as controls. $\mathrm{CO}_{2}$ emissions were calculated with car kilometers driven per car owner living in areas studied. There was a $1.6 \%$ decline in average distance travelled per passenger vehicle by the third year of the intervention. A $1 \%$ reduction of $\mathrm{CO}_{2}$ emissions was found three years following the intervention. The authors explained that active transport increased by $30 \%$, but this represented only a $5.3 \%$ decrease in the number of motorized trips. Second, two studies separately examined the longitudinal changes of active travel behaviors and $\mathrm{CO}_{2}$ emissions after the construction of new high-quality walking and cycling routes in three UK cities $[59,60]$. These new infrastructures were associated with population-level increases in selfreported walking, cycling and physical activity at the two-year follow-up. However, after the intervention, the reduction in the proportion of transport emissions attributable to car travel was negligible, from $89 \%$ at baseline, to $88 \%$ at one-year and $86 \%$ at the two-year follow-up. Finally, Mrkajic et al. [61] tested the effect of a bike parking improvement intervention (e.g., shelters, toast-shape racks with $\cap$-shape) at the Faculty of Technical Sciences of Novi Sad (Serbia) on active transport. They coupled observational data with an online survey. Occupancy rate was a proxy of active transport. After adjustment for other transport modes, the intervention resulted in a reduction of $\mathrm{CO}_{2}$ emissions by $50 \%$ in one year.

\subsubsection{Observational studies}

Zhang and $\mathrm{Mi}$ [62] estimated the role of a bike share system on $\mathrm{CO}_{2}$ and nitrogen oxide (NOx) emissions in Shanghai (China). They analyzed data from Mobike, a major company of dockless shared bikes representing more than one million trips in 2016 . The average daily trip distance and time were $2.2 \mathrm{~km}$ and 16.8 minutes, respectively. According to the authors' estimations, the shared bike system avoided the emission of 25,240 tons of $\mathrm{CO}_{2}$ (i.e., roughly equivalent to emissions from the annual energy use of approximately 2,300 homes in the US) and 64 tons of NOx in Shanghai. Winslott et al. [63], through a websurvey among Swedish electrical bike (e-bike) owners, examined the self-reported impact of e-bike use on other modes of transport and then derived possible $\mathrm{CO}_{2}$ reductions associated with this transport mode. Respondents living in urban or rural areas replaced $55 \%$ and $79 \%$ of car trips by e-bike. E-bike use also resulted in a decrease of $14-20 \%$ of the average total $\mathrm{CO}_{2}$ emissions from transportation per person.

\subsubsection{Scenario-based studies}

A systematic review compiled studies using computerized simulations to estimate the effects of shifts from motorized trips to active travel modes on gas emissions [64]. All six studies included in the review concluded that increases active transport were related to lower greenhouse gas emissions. The degree to which gas emissions were reduced was, however, highly heterogeneous depending on the simulations, hypotheses, contexts and the gas studied (e.g., $\mathrm{CO}_{2}, \mathrm{CH} 4$ or $\mathrm{CO}_{2}$ equivalent emissions).

Bucher et al. [65] compared four different transportation scenarios on greenhouse gas 
emissions in Switzerland. The authors simulated four modes of commuting for work: traditional car only, electrical vehicles only, e-bike and e-bike/electric vehicle combination. The combination e-bike/electric vehicle scenario was associated with the most important greenhouse gas reduction (17.5\%). The ebike scenario was related to a $10 \%$ decrease. These reductions fluctuated according to season, temperature and rain. For example, models estimated that a minimal acceptable temperature threshold was $10{ }^{\circ} \mathrm{C}$ for e-bike use, and $15^{\circ} \mathrm{C}$ when raining.

Maizilsh et al. [66] quantified potential reductions in greenhouse gas emissions in three scenarios for short trips in the San Fransisco Bay area (US) in 2035. They computed greenhouse gas emissions for "low carbon" driving options (i.e., gaselectric hybrid vehicles, light-duty diesel, biofuel, electric vehicles), active transport (i.e., $50 \%$ of miles traveled in car trips $<1.5$ miles are walked and $50 \%$ of miles travelled in car trips between 1.5 to 5 miles are bicycled) and a combination of both scenarios. Combined scenarios were associated with the most important reduction of greenhouse gas emissions. The authors found that the contribution of the physical activity only scenario was not substantial in terms of greenhouse gas emissions.

Rojas-Rueda et al. [67] simulated the effects of two active transport scenarios on $\mathrm{CO}_{2}$ reduction in six European cities (Warsaw, Prague, Barcelona, Paris, Copenhagen and Basel). The first scenario expressed a shift of $35 \%$ of all trips by bicycle (i.e., the level of cycling in Copenhagen) and the second scenario represented a shift by $50 \%$ of all trips walking (i.e., the level of walking in Paris). In the first scenario (cycling), Paris, Prague and Warsaw were the three cities with the most important $\mathrm{CO}_{2}$ reduction (estimated 19.9, 22.8, and 26.4 metric tons per year, respectively) given that their initial levels of cycling were lowest. In the second scenario (walking), the $\mathrm{CO}_{2}$ reduction in Prague and Warsaw was the most important (8.3 and 11.6 metric tons per year) for the same reasons.

Creutzig et al. [68] compared $2010 \mathrm{CO}_{2}$ emissions in Barcelona (Spain), Freiburg (Germany), Malmo (Norway) and Sofia (Bulgaria) to four policy scenarios with increasing shifts from motorized transport to public and active transport. These policy scenarios were associated with a reduction of $\mathrm{CO}_{2}$ emissions ranging from $40 \%$ to $60 \%$ in comparison to 2010 values. Anticipated reductions could be more important in smaller cities (Freiburg and Malmö) because active transport could be the dominant transport mode [68].

It is important to note that possible $\mathrm{CO}_{2}$ emission reductions could be decreased by a potential negative feedback loop from food production and consumption. A massive development of active transport could be associated with an increase of individual food-related greenhouse gas emissions due to increased energy expenditure [69]. In the most economically developed countries, one kilometer travelled by walking and cycling could result in greenhouse gas emissions of up to 0.26 and $0.14 \mathrm{~kg}$ $\mathrm{CO}_{2}$ per kilometer, respectively [69].

\subsubsection{Theme 4: Carbon footprint among sport participants}

Of the eight studies included in this section, four dealt with the carbon footprint of sport participants and four with the carbon footprint of elite athletes.

\subsubsection{Sport participants}

Wicker [70] examined the carbon footprint associated with sport participation in Germany via an online survey. Based on 6,500 respondents, twenty different sports were assessed. The author calculated an individual annual carbon footprint of sport-related travel representing different purposes: weekly activity, competitions, league games, day trips and vacation. The average individual annual carbon footprint amounted to $844 \mathrm{~kg} \mathrm{CO}$, representing almost $8 \%$ of overall emissions for a German adult. Individuals' average annual carbon footprint was $1,006 \mathrm{~kg}$ of $\mathrm{CO}_{2}$ for individual sports, and $514 \mathrm{~kg}$ of $\mathrm{CO}_{2}$ for team or racket sports. The three highest individual carbon footprints, which exceeded $2,000 \mathrm{~kg} \mathrm{CO}$, were found in participants practicing diving, golf and surfing. Their carbon footprint was mainly driven by vacation related travels. In addition, Wicker [71] computed the annual 2015 carbon footprints of snow-sport related travels in German adults and found an average carbon footprint of $431 \mathrm{~kg} \mathrm{CO}$. Snow boarders in comparison with skiers produced a higher annual carbon footprint (519 vs $332 \mathrm{~kg} \mathrm{CO}$ ).

Chard and Mallen [72] examined the carbon footprint of two youth ice hockey teams in Canada for an entire season. The carbon footprint was estimated at $760 \mathrm{~kg} \mathrm{CO}_{2}$ for elite team players and $530 \mathrm{~kg} \mathrm{CO}$ for players at a lower competitive level. Furthermore, Bunds et al. [73] estimated the carbon footprint of a regional competitive youth swimming team in North Carolina (US). They sent text messages to 172 parents over three weeks to assess their car use when driving children to swimming pools. The overall carbon footprint was $8,810 \mathrm{~kg} \mathrm{CO}$ over three weeks of the program for the 153 included families. The projected carbon footprint for the entire season with all families $(\mathrm{N}=450)$ over 47 weeks amounted 415 tons of $\mathrm{CO}_{2}$. The investigators performed three different simulation analyses to explore the $\mathrm{CO}_{2}$ emission reductions related to carpooling ( $\geq 3$ to 5 children for each car), use of cars with low fuel consumption (i.e., $\leq 7.8$ liters per 100 kilometers) and use of practice facilities within the closest geographic proximity. The carpooling or 
exclusive low consumption car use could both result in a $40 \%$ reduction in total combined $\mathrm{CO}_{2}$ emissions per child. The third strategy - proximity of the facilities was related to a small improvement (i.e., $12 \%$ reduction).

\subsubsection{Athletes}

The carbon footprint of athletes has been investigated in soccer, Formula one and university sport teams. Tóffano et al. [74] estimated the carbon footprint of English Premier Leagues soccer clubs during the 2016-17 season. Overall, this season represented more than 1,134 tons of $\mathrm{CO}_{2}$ for the 20 teams involved in the championship. The carbon footprint of each club member was 29 tons $\mathrm{CO}_{2}$. Most of their greenhouse gas emissions were generated by air travels and luxury accommodation facilities.

Dolf and Teehan [75] quantified the carbon footprint of University sport teams (University of British Columbia, Canada, season 2011-2012). Athletes traveled exclusively by plane. The average carbon footprint per team member was $59 \mathrm{~kg} \mathrm{CO}$ per event. The total carbon footprint for the team was 630 tons $\mathrm{CO}_{2}$ for one season. On the other hand, the carbon and $\mathrm{NO}_{x}$ footprints of athlete students at University of Montreal were 0,5 tons and $0.10 \mathrm{~kg}$, respectively. Their trips were mainly completed by bus [76]. Finally, Mourao [77], estimated that a professional car race resulted in 54 tons of $\mathrm{CO}_{2}$ per driver including flights, staff travels, and production of raw materials. In their estimation, $\mathrm{CO}_{2}$ emissions associated with races and testing represented only $0.3 \%$ of emissions per driver. A time series analysis was also performed to explore the efficacy of specific Formula One regulations developed in 2009 and targeting a reduction in $\mathrm{CO}_{2}$ emissions [77]. However, these regulations were not associated with a reduction in $\mathrm{CO}_{2}$ emissions between 2012 to 2015.

\subsubsection{Theme 5: Natural disasters and physical activity}

Fifteen studies focused on the associations between natural disasters and physical activity/sport participation, organizations or infrastructure. Three categories were created to synthesize the literature: associations between natural disasters and individual physical activity behaviors $(\mathrm{N}=6)$; associations between natural disasters and physical activity/sport organizations $(\mathrm{N}=8)$ and the role of physical activity/sport infrastructure in post-disaster settings $(\mathrm{N}=3)$. The natural disasters represented here were hurricanes/cyclones, floods, droughts and typhoons.

\subsubsection{Associations between natural disasters and physical activity \\ A cross-sectional analysis of the Health Retirement Study (2000-2014) examined whether}

exposure to natural events (characterized by a federal disaster declaration impact) was associated with health behavior change in a large sample of participants aged 55 years and older [78]. During the study period, $60 \%$ of respondents were exposed to one or more of these disasters. Results highlighted that older adults exposed to natural disasters were more likely to decrease their self-reported vigorous physical activity. Another cross-sectional study (US) examined the potential impact of Hurricane Ike in 2008 on children's levels of self-reported sedentary activities 8-months after the hurricane [79]. High perceived stress related to the hurricane and post-traumatic stress symptoms were significantly associated with more time spent in sedentary activities and lower time spent in outdoor physical activity. Authors recommended, for example, to rebuild playgrounds or make them accessible quickly after a disaster to help children return to their normal routines.

A survey was conducted in 32 parks in New Orleans (US) during the summer of 2006 and 2007 following Hurricane Katrina [19]. Investigators compared visit frequency and park use experiences among park visitors from flooded versus non-flooded areas of New Orleans. Visitors from flooded neighborhoods used parks less frequently.

Tabrizi et al. [80] compared health conditions of adults living in areas adjacent and far from lake Umia in Iran (i.e., the second largest saline lake in the world). Lake Urmia is subject to frequent and massive droughts and forms an area of "salt desert" bringing chemicals very close to urban and rural habitats. No significant differences were found in self-reported physical activity between participants living in Lake Urmia's adjacent areas and control areas.

A study in Houston (US) investigated the impact of the 2017 Hurricane Harvey on continuously collected data of bicycle and pedestrian trail use [81]. Time series analyses showed that this natural event had a significant negative impact on physical activity (e.g., reduced daily pedestrian and bicycle counts). However, daily pedestrian and bicycle counts returned to pre-hurricane levels by 6 weeks post-landfall. This study shed light on the potential role of bicycle and pedestrian infrastructure on disaster recovery and well-being among affected populations.

Abad et al. [82] explored the impact of repeated floods over the last decade in public transit commuters in Manilla (Philippines). Participants were questioned about their commuting behavior adaptations and reported that they commuted less by walking due to repeated floods.

\subsubsection{Sport and physical activity organizations post-disaster \\ A detailed examination of 70 newspaper and magazine articles revealed that athletes and related}


sport organizations can provide support to local communities after a disaster [83]. Authors classified post-disaster sport organizations' support as tangible (i.e., provision of resources) and emotional (i.e., provision of activities enhancing well-being postdisaster). Tangible social support activities included monetary, matching and in-kind donations, fundraising activities, volunteering and shelter (e.g., using athletic facilities to house evacuees after flooding). Emotional social support involved site visits (e.g., NFL players visiting victims of Hurricane Katrina), community development programs (e.g., professional athletes working with local athletes to redevelop cricket clubs) and memorials.

Orr and Inoue [84] published a conceptual paper characterizing climate change vulnerability for sports organizations, by adapting the IPCC and United Nations International Strategy for Disaster Reduction guidelines to sport organizations. The authors suggested that sport organizations should anticipate the impacts of climate change on their equipment, finances, and the experiences of their athletes, staff, and spectators. They added that sport organizations would be impacted differently based on their level of exposure (e.g., latitude, precipitation). In this perspective, they stressed the importance for sport organizations to develop new capabilities to adapt their operations to minimize disruptions and additional costs.

Wicker et al. [85] examined determinants of post natural disaster (flooding, cyclone) resilience in 200 Australian sports clubs. The capacity to mobilize members and volunteers, coupled with public grants, were the two major factors associated with greater resilience post disaster. A sub-sample of community sport club managers, members and partners also participated in focus groups and interviews. Results echoed previous findings, highlighting the major role of local partners and sponsors in providing labor and equipment following disasters [86].

Kirkpatrick $[87,88]$ qualitatively investigated how bicycling enthusiasts have organized community events in US cities to demonstrate how bicycles may be useful during natural a natural disaster event. Citizen cyclists have developed community bike races known as "disaster relief trials". Riders use a cargobicycle to haul large and fragile items, and must cross water, rough terrain and physical barriers designed to simulate disaster conditions. The trials are developed to improve community resilience in case of natural disasters. These qualitative studies highlighted that there are a variety of tasks that citizens cyclists could undertake post-disaster, such as delivery of food, water, medication and messages. However, study participants stressed that disasters such as floods, blizzards and wildfires were not realistic scenarios for bicycle use. Respondents also added that formal emergency management system may develop a coordination system with this kind of citizen initiative in the future.

Three included studies reported the existence of post-disaster physical education programs developed for children impacted by natural disasters. A quasi-experimental trial carried out in Leyte (Philippines) one year after typhoon Haiyan (2013) explored the effects of a sport intervention in schools on adolescents' self-esteem [89]. The investigators proposed a coaching-education workshop for teachers and four student "leaders" in each class. The workshop promoted development of a mastery motivational climate through a 2-month sport intervention. Two other schools were used as the control group. After the 2-month program, self-esteem levels were higher in students participating in sportbased activities. The authors discussed the role of physical activity and sport programs for youth mental health following disasters. Two US departments of kinesiology have also been involved in the development and implementation of physical activity programs post-disaster [90,91]. However, their effectiveness has not been assessed. After Hurricane Katrina, the US government opened a trailer park for 14,000 people named "Renaissance Village" (October 2005). Residents were predominantly African American, with low income; $30 \%$ were under 18 years of age, and $80 \%$ were not enrolled in school. In June 2006, the kinesiology department from Louisiana State University instituted a structured and fun-filled physical activity program (4 weekly sessions of 2 hours) named "LE PAS" for children living in the park. The main goal was to reduce stress and improve overall health in school-age children impacted by the hurricane [90]. Similarly, after a series of devastating tornadoes in 2011 (>5,000 homes destroyed), the kinesiology department of University of Alabama developed an after-school program combining soccer-related activities with group sharing sessions for children affected by these events [91]. A reduction in stress and anxiety was expected in the participants.

3.2.5.3 Role of physical activity/sport
infrastructure post-disaster
A cross-sectional study assessed neighborhood rebuilding preferences among 442 New Orleans residents after Hurricane Katrina in 2006 [92]. Results showed that residents' top priority was to reduce crime and disorder; nonetheless, all groups supported neighborhood features that promote physical activity (i.e., sidewalks, crosswalks, parks and playgrounds). The authors suggested that, after neighborhood safety, physical activity infrastructure may also be an important aspect for communities' well-being after a natural disaster. In the survey by Rung et al. [19] previously presented, the authors compared park use experiences among park visitors 
from flooded versus non-flooded areas of New Orleans during the summer of 2006 and 2007. Among park visitors from flooded areas, "escape reasons" (i.e., to help release tension and forget daily responsibilities) were among the most frequent park use experiences reported.

Finally, a qualitative investigation examined the role of recreation park use before, during and after devastating level 5 tornadoes in Oklahoma and Missouri (US) [93]. Park employees were interviewed on site and exposed to photos and videos. These participants highlighted the importance of rebuilding aquatic facilities and playground equipment after disasters to improve neighborhood well-being. Park employees suggested that leisure physical activity in parks was associated with a better resilience in those communities.

\subsubsection{Theme 6: Future of physical activity and sport practices in a changing world}

Ten studies were included in this section. Three studies simulated projections for future Olympic Games, four studies examined outdoor physical activity around $2060-2080$, and three studies proposed a revised definition of physical activity in regard to environmental concerns.

\subsubsection{Scenario-based studies}

3.2.6.1.1 Olympic Games

Based on RCP 2.6 and 8.5 scenarios, Scott et al. [94,95] determined the climate suitability for previous Olympic locations to host Olympic and Paralympic Winters Games in 2080. They added two criteria: the probability of minimum daily temperatures under $0{ }^{\circ} \mathrm{C}$ and minimum snow depth $\geq 30 \mathrm{~cm}$. According to their estimations, 12 and 10 sites out 21 cities would be suitable to host Olympic and Paralympic Winters Games, respectively, for the low emissions scenario. However, only $8 / 21$ and $4 / 21$ were still suitable to host these Games in a high emissions context. Paralympic Games would be more vulnerable because they are scheduled later in the winter (March).

The impacts of climate change on summer Olympic Games were also investigated. Smith et al. [96] simulated climate models assuming a high emissions scenario (RCP 8.5) in 2085. They included cities with populations $>600,000$ and below $1,600 \mathrm{~m}$ in elevation in the northern hemisphere. They used a $26{ }^{\circ} \mathrm{C}$ WBGT threshold to categorize low-risk cities. According to their projections, in Western Europe, only $24 \%(25 / 102)$ of included cities might be suitable to host Summer Olympic Games in 2085. However, in other geographical areas, only 1.5\% (8/543) might still be suitable to host the Olympic Games. None of the eligible cities were in North Africa or Latin America/Caribbean.

\subsection{Outdoor activities}

The US Forest Services estimated the impact of climate change on outdoor recreation activities in 2060 in four forest service regions: North, South, Rocky Mountain, and Pacific Coast regions (representing all US) [97]. Three IPCC scenarios were used including projections of population growth, economic growth, bioenergy use and local variation of temperature. Scenarios also varied in terms of severity of greenhouse gas emissions. Among 17 outdoor recreation activities, 9 were related to physical activity (i.e., climbing, horseback riding, hiking, hunting, fishing, skiing, snowshoeing, swimming and canoeing). Climate change effects had mixed impacts on active outdoor activities across regions and were not always negative. The most negative impacts occurred in the North region, with a decrease of participants in 7/9 activities. Snowshoeing, hunting and canoeing were the most affected activities. Various patterns were observed in terms of activities between regions. For example, an increase in the number of participants was identified for 1 or 2 activities in three regions.

Three studies modelled the outdoor skating season duration in Ottawa and Montreal (Canada) based on the "business as usual" scenario (RCP 8.5) [98-100]. The reduction of the outdoor skating season ranged from $24 \%$ to $75 \%$ by 2090 . Increasing temperature variability during winter could be an exacerbating factor.

An examination of climatic conditions for cross-country skiing with an international perspective for 2065 and 2100 was performed using projections from the IPCC's fifth assessment report [101]. The season would be shorter due to warmer winters, increased winter precipitation, and faster snowmelt. Furthermore, spring or summer events such as increased slope failure, forest fires and flooding would result in worse conditions for cross-country skiing [101].

\subsubsection{Conceptual studies}

A definition of "sustainable physical activity" has been recently proposed by Bjørnarå et al. [102], defined as: "activities that are conducted with sufficient duration, intensity and frequency for promoting health, yet without excessive expenditure of energy for food, transportation, training facilities or equipment. Sustainable physical activities have low environmental impact, and they are culturally and economically acceptable and accessible". These authors also developed the Healthy and Sustainable Dietary and Physical Activity habits score to examine the sustainability of physical activity practices in future epidemiological investigations [103]. They argued that sustainable physical activity should come with an important investment in active transport, developments in community physical activity practices 
and a reduction of equipment and appliances used in daily tasks (e.g., shoveling snow by hand versus using a snow blower).

Malchrowicz-Mosko et al. [104] developed the "slow sport" concept. Their proposition is in line with other "slow movements" (e.g., slow food, slow science) as a strategy to cope with climate change. Slow sport was defined by a physical practice focused on pleasure, without interest in performance. They compared the level of satisfaction between halfmarathon runners who achieved or did not achieve their sport goals, to runners without goals. No significant differences were found between runners with or without performance goals.

\subsubsection{Theme 7: A conceptual model about climate change and physical activity}

Table 1 proposes a summary of the main findings for each theme. Figure 3 presents a more complex synthesis of these associations between climate change impacts and different physical activity characteristics. Flags represent findings that could be specific to a country or geographical area. A distinction between empirical and scenario-based studies is proposed. The greenhouse gas reduction expected with active transport development in scenario-based studies was very modest in empirical studies. Sport participation was related to a higher carbon footprint, particularly in elite athletes. Heat waves were associated with a drastic reduction of physical activity. However, thresholds varied by latitude and season. For instance, southern states in the US will be more frequently exposed to heat waves and shorter winters in the future. Consequently, physical activity patterns will be more negatively and positively impacted during summer and winter, respectively. Exposure to natural disasters was associated with lower vigorous physical activity and active transport frequency. However, no significant association was found between drought and active transport frequency. Increased air pollution was related to a decrease in active transport and leisure physical activity, and increased time spent in sedentary activities.

\section{Discussion}

Climate change and physical activity are two major issues impacting human well-being and behavior. The present review provides, for the first time, a broad overview of the associations between physical activity and several climate change outcomes. By doing so, this work highlights some of the current and future challenges that physical activity and sport communities, including stakeholders, athletes, healthcare providers and academic communities, will have to address in the coming years.

The identified articles were classified into six themes: physical activity and air pollution, physical activity and extreme weather conditions, physical activity and greenhouse gas emissions, physical activity and carbon footprint, physical activity and natural disasters and futures of physical activity practices in a changing world. We then proposed a conceptual model presenting a multidimensional and interconnected approach of climate change and physical activity and sport practices based on the results of our review.

Overall, results indicate a consistent negative effect of air pollution, extreme temperatures and natural disasters on physical activity. In line with four RCP scenarios for 2030, 2050, and 2100, the expected increase of air pollution [105], frequency and duration of extreme temperature episodes and natural disaster intensity will negatively impact physical activity patterns mid- and long-term. This physical activity reduction will be more severe in adults with chronic diseases, higher body mass index and the elderly. Furthermore, health risks attributable to air pollution and extreme weather could be exacerbated through active transport in adults living in the most deprived areas. Indeed, walking or biking might be the only travel mode in adults with low income [106]. Previous reviews also suggested a possible "positive impact" of temperature increases during cold seasons $[24,25]$. However, these benefits could be very temporary and geographically localized. From a global perspective, physical activity prevalence could drastically decrease in subtropical regions (e.g., Australia), and be more exposed to seasonal variations in northern temperate regions (e.g., Canada) [26]. Potentially positive effects are difficult to interpret in isolation from other concomitant effects of climate change such as increases in sea levels, which will probably result in profound changes for our societies in the coming years [107].

Regarding the effects of physical activity on climate change outcomes, results suggest that physical activity has two concurrent mitigation and amplification roles towards climate change. The development of active transport combined with public transport development and utilization of low- emission cars are associated with reduced greenhouse gas emissions in urban environments. Furthermore, sport and leisure physical activity communities are recognized as important promoters of population resilience following natural disasters. For instance, bicycles might provide a means to reach isolated people after a hurricane, and adapted sport interventions can be organized to improve well-being in children exposed to natural disasters. On the other hand, the sport industry is an important source of greenhouse gas emissions. These emissions are mainly driven by motorized transport required for physical activity participation. These findings were found for leisure, tourism and professional sport 
activities. However, if physical activity-related travel represented $2.2 \%$ to $26 \%$ of the annual carbon footprint in German active adults [70], the annual carbon footprint of an English Premier League player [74] or professional race car driver [77] represents 5.3 and 10 times the annual carbon footprint of British adults (i.e., 5.4 tons per year).

Our framework presented several plausible climate change-physical activity feedback loops. However, other human behaviors should be integrated in future frameworks because negative or positive feedback loops can be anticipated. For example, an increase in daily physical activities could potentially increase individuals' carbon footprint due to higher food consumption [70] but also improve sleep quality $[7,108]$. Other human behaviors will also likely be affected by climate change impacts (e.g., negative effect of rising global temperatures on sleep) and ultimately trigger a decrease in physical activity [109]. For instance, an increase of $35 \%$ in vehicle miles travelled is expected in RCP 8.5 in the US [109].

Occupational physical activity and active travel could be considered as at-risk behaviors in a context of heat waves or pollution alerts. A decrease in moderate to vigorous physical activity during high temperatures was found in the included studies, but only one examined occupational physical activity. Consequently, it could be anticipated that outdoor workers (such as gardeners and construction workers) would decrease or stop their activities during these periods.

The literature review also suggests that physical activity and sport definitions could be revised by including a climate change perspective in current and future practices. The sustainable physical activity or slow sport concepts are in line with rising moral questions in this domain [110], as highlighted by several examples in recent years. For instance, the Formula One driver Lewis Hamilton reported suffering ecoanxiety [111]. The 2019 Doha World Athletics Championships were organized in weather conditions that were unreasonable for athletes [110]. Moreover, greenwashing strategies of international sport federations have been revealed [112]. For instance, the Fédération Internationale de Football Association 2006 World Cup was presented as a "climate-neutral" event, but environmental audits did not include sport teams and spectator air travels [112]. In his analysis about sport, Breivik [113] concluded: "With increasing global warming and climate change we may have not only an option but an obligation to change present sport practices". Many recent international sport competitions have been impacted by climate related events in the past years, such as the last rugby world cup in Japan (Typhoon Hagibis). The impact of climate change on the organization of such international competitions will probably become more and more salient in the upcoming years.

\subsection{Limitations}

This systematic review has limitations. Because physical activity is studied in various scientific disciplines and characterized in various forms (e.g., leisure activity, health behavior, transport), it is possible that relevant studies were missed. We also did not include grey literature or international reports. Thus, regional or international initiatives examining the impacts of climate change on physical activity or sport may be missing. Finally, computerized simulation studies were performed with very different levels of complexity, from two temperatures indicators [17] to scenarios including population, economic, and bioenergy indicators [98]. Consequently, findings from these studies should be interpreted cautiously.

\subsection{Future research}

Based on this systematic review, we propose seven research perspectives that might help the physical activity community to anticipate and mitigate climate change impacts:

1. Future research should be undertaken to explore how occupational physical activity will be impacted and regulated in the context of extreme weather events. For instance, how can we limit heatwaverelated risks for delivery riders, farmers or construction workers? To date, studies have focused on leisure time physical activity and active transport. More studies on occupational physical activities are necessary.

2. Research projects designed and conducted by researchers in low- and middle incomes countries should explore the possible adaptation and mitigation role of physical activity for different climate change outcomes. As shown in Figure 2, there is a paucity of work conducted in low and middle-income countries and more studies are needed in various geographical areas.

3. Rising sea levels and natural disasters will push people to migrate within their country or abroad [114]. Physical activity or adapted sport interventions as development tools should be used in line with recent knowledge from "Sport for development" [114] and "Sustainable Development Goals" [115] to promote their social integration and help climate refugees to cope with post-natural disaster health consequences.

4. The increasing occurrence of vector-borne diseases (e.g., Lyme disease, malaria) associated with climate change [11] may impact physical activity behaviors such as active travel, occupational physical activities and outdoor physical activities. Outdoor physical activities (e.g., hiking, lumberjack) could be associated with higher risk of being exposed to some specific diseases (e.g., Lyme disease) [116]. Consequently, a 
negative perception could be associated with these activities in population. Prospective studies could also examine how infected individuals recover from these diseases depending on their physical activity level.

5 . Research to identify the consequences of rising sea levels or thawing ice on physical activity practices would be beneficial. For instance, cultural physical activities can be disrupted in Small Island Developing States or among native people living in sub-polar regions.

6. More studies should quantify the carbon footprint of (inter)national, university sport competitions, and leisure sport practices, particularly in countries that are large emitters of greenhouse gases. Guidelines should be developed to ultimately limit the $\mathrm{CO}_{2}$ emissions from these sectors and promote sustainable sport management practices (see e.g., [117]).

7. The first narrative model developed in the present article (Figure 3 ) should be extended to a computational model (i.e., a model allowing to simultaneously consider all its components and to make concrete projections about potential future scenarios from a complex scientific perspective). Such a model might help to anticipate future impacts of climate change on physical activity by considering feedback loops and complex set of relationships [109].

\subsection{Recommendations}

Five recommendations for physical activity stakeholders, academic communities and coaches can be made from the present review. First, climate change impacts increasingly and disproportionately affect physical activity at a worldwide scale. Consequently, future physical activity guidelines should present the risks (e.g., heat waves) and possible benefits for physical activity related to climate change (i.e., reduction of air pollution, greenhouse gas). Second, climate change impacts and adaptation/mitigation roles of physical activity should be systematically included in kinesiology/sport sciences courses. Third, physical activity and sport communities should be involved in regional preparedness plans for natural disasters. Fourth, a thorough revision of transport modes related to leisure sport practices and professional sports need to be developed. (Inter)national competitions must be reorganized in order to significantly decrease the carbon footprint of athletes. For instance, permanent Olympic locations can be selected based on future climate change scenarios and their accessibility. Also, short domestic flights can be replaced by more energy-efficient modes of travel in national championships. Finally, our findings highlight that climate change is transforming physical activity practices and communities. In this vein, the definition of physical activity definition should be revised to include climate change perspectives and consequences.

\section{Conclusion}

Our review highlights bidirectional associations between climate change, physical activity and sport practices. Air pollution, extreme weather and natural disasters directly influence physical activity. Physical activity communities also can play a resilience role following natural disasters. Regarding greenhouse gas emission, physical activity is part of the problem and part of the solution. This is a particularly important aspect to understand among the top ten greenhouse gases emitting countries (US, China, Russia, Brazil, India, Germany, the United Kingdom, France, Indonesia and Canada) [118] generating more than $60 \%$ of total emissions. Stakeholders, sport industries, athletes, sport communities and sport researchers from these countries must be aware of the climatic emergency and work to actively reduce the carbon print associated with physical activity practices and avoid greenwashing strategies [119]. 


\section{References}

1. Crutzen. Geology of mankind. Nature. 2002;415:23.

2. Steffen W, Rockström J, Richardson K, Lenton TM, Folke C, Liverman D, et al. Trajectories of the Earth System in the Anthropocene. Proc Natl Acad Sci. 2018;115:8252-8259.

3. Ripple WJ, Wolf C, Newsome TM, Galetti M, Alamgir M, Crist E, et al. World Scientists' Warning to Humanity: A Second Notice. BioScience. 2017;67:1026-8.

4. Intergovernmental Panel on Climate Change. Global warming of $1.5^{\circ} \mathrm{C}$ [Internet]. 2018 [cited 2018 Dec 11]. Available from: http://www.ipcc.ch/report/sr15/ 5. Hoeppe P. Trends in weather related disasters Consequences for insurers and society. Weather Clim Extrem. 2016;11:70-9.

6. Intergovernmental Panel on Climate Change. IPCC Special Report on the Ocean and Cryosphere in a Changing Climate [Internet]. 2019 [cited 2018 Dec 11]. Available from: https://www.ipcc.ch/site/assets/uploads/sites/3/2019/1 1/SROCC_FinalDraft_FullReport.pdf

7. Rifkin $\overline{\mathrm{DI}}$, Long $\mathrm{MW}$, Perry MJ. Climate change and sleep: A systematic review of the literature and conceptual framework. Sleep Med Rev. 2018;42:3-9.

8. Watts N, Amann M, Ayeb-Karlsson S, Belesova K, Bouley T, Boykoff M, et al. The Lancet Countdown on health and climate change: from 25 years of inaction to a global transformation for public health. The Lancet. 2018;391:581-630.

9. Watts N, Amann M, Arnell N, Ayeb-Karlsson S, Belesova K, Boykoff M, et al. The 2019 report of The Lancet Countdown on health and climate change: ensuring that the health of a child born today is not defined by a changing climate. The Lancet [Internet]. 2019 [cited 2019 Nov 14];0. Available from: https://www.thelancet.com/journals/lancet/article/PIISO 140-6736(19)32596-6/abstract

10. Zywert K. Human health and social-ecological systems change: Rethinking health in the Anthropocene. Anthr Rev. 2017;4:216-38.

11. Whitmee S, Haines A, Beyrer C, Boltz F, Capon $A G$, Dias BF de $S$, et al. Safeguarding human health in the Anthropocene epoch: report of The Rockefeller Foundation-Lancet Commission on planetary health. The Lancet. 2015;386:1973-2028.

12. Butler C. Sounding the Alarm: Health in the Anthropocene. Int $\mathrm{J}$ Environ Res Public Health. 2016;13:665

13. Ebi KL, Frumkin $\mathrm{H}$, Hess JJ. Protecting and promoting population health in the context of climate and other global environmental changes. Anthropocene. 2017;19:1-12.
14. Levy BS, Sidel VW, Patz JA. Climate Change and Collective Violence. Annu Rev Public Health. 2017;38:241-57.

15. Berry HL, Waite TD, Dear KBG, Capon AG, Murray $V$. The case for systems thinking about climate change and mental health. Nat Clim Change. 2018;8:282-90.

16. Obradovich $\mathrm{N}$, Fowler $\mathrm{JH}$. Climate change may alter human physical activity patterns. Nat Hum Behav. $2017 ; 1$.

17. Saneinejad S, Roorda MJ, Kennedy C. Modelling the impact of weather conditions on active transportation travel behaviour. Transp Res Part Transp Environ. 2012;17:129-37.

18. Maloney SK, Forbes CF. What effect will a few degrees of climate change have on human heat balance? Implications for human activity. Int $\mathrm{J}$ Biometeorol. 2011;55:147-60.

19. Rung AL, Broyles ST, Mowen AJ, Gustat J, Sothern MS. Escaping to and being active in neighbourhood parks: park use in a post-disaster setting. Disasters. 2011;35:383-403.

20. Bernard P. Health psychology at the age of Anthropocene. Health Psychol Behav Med. 2019;7:193-201.

21. Shaw C, Hales S, Howden-Chapman P, Edwards $R$. Health co-benefits of climate change mitigation policies in the transport sector. Nat Clim Change. 2014;4:427-33.

22. Woodcock J, Edwards P, Tonne C, Armstrong BG, Ashiru $O$, Banister $D$, et al. Public health benefits of strategies to reduce greenhouse-gas emissions: urban land transport. Lancet Lond Engl. 2009;374:1930-43.

23. Yang W, Sim T, Cui K, Zhang J, Yang Y, Ma X. Health-Promoting Lifestyles Among Health Care Workers in a Postdisaster Area: A Cross-sectional Study. Disaster Med Public Health Prep. 2019;13:230235.

24. Townsend M, Mahoney M, Jones JA, Ball K, Salmon J, Finch CF. Too hot to trot? Exploring potential links between climate change, physical activity and health. J Sci Med Sport. 2003;6:260-5.

25. Wallace JP, Wiedenman E, McDermott RJ. Physical Activity and Climate Change: Clear and Present Danger? Health Behav Policy Rev. 2019;6:534-545.

26. Change IP on C. Climate Change 2014: Impacts, Adaptation, and Vulnerability [Internet]. 2014. Available from: https://www.ipcc.ch/report/ar5/wg2/

27. Jones CM, Kammen DM. Quantifying Carbon Footprint Reduction Opportunities for U.S. Households and Communities. Environ Sci Technol. 2011;45:4088-95.

28. Moher D, Liberati A, Tetzlaff J, Altman DG, PRISMA Group. Preferred reporting items for 
systematic reviews and meta-analyses: the PRISMA statement. PLoS Med. 2009;6:e1000097.

29. Change IP on C. High Mountain Areas in Special Report on the Ocean and Cryosphere in a changing climate [Internet]. 2019. Available from: https://www.ipcc.ch/srocc/chapter/chapter-2/

30. An R, Ji M, Zhang S. Global warming and obesity: a systematic review: Global warming and obesity. Obes Rev. 2018;19:150-63.

31. Gao J, Kovats S, Vardoulakis S, Wilkinson P, Woodward A, Li J, et al. Public health co-benefits of greenhouse gas emissions reduction: A systematic review. Sci Total Environ. 2018;627:388-402.

32. Lawrence S, De Silva M, Henley R. Sports and games for post-traumatic stress disorder (PTSD). Cochrane Common Mental Disorders Group, editor. Cochrane Database Syst Rev. 2010;

33. Vaugeois $N$, Parker $P$, Yang $Y$. Is leisure research contributing to sustainability? A systematic review of the literature. Leisure/Loisir. 2017;41:297-322.

34. Zhong S, Yang L, Toloo S, Wang Z, Tong S, Sun X, et al. The long-term physical and psychological health impacts of flooding: A systematic mapping. Sci Total Environ. 2018;626:165-94.

35. Rodgers $M$, Sowden $A$, Petticrew $M$, Arai $L$, Roberts $\mathrm{H}$, Britten $\mathrm{N}$, et al. Testing Methodological Guidance on the Conduct of Narrative Synthesis in Systematic Reviews: Effectiveness of Interventions to Promote Smoke Alarm Ownership and Function. Evaluation. 2009;15:49-73.

36. South A. rworldmap: a new $R$ package for mapping global data. R J. 2011;3:35.

37. An R, Zhang S, Ji M, Guan C. Impact of ambient air pollution on physical activity among adults: a systematic review and meta-analysis. Perspect Public Health. 2018;138:111-21.

38. Laffan K. Every breath you take, every move you make: Visits to the outdoors and physical activity help to explain the relationship between air pollution and subjective wellbeing. Ecol Econ. 2018;147:96-113.

39. Yu H, Yu M, Gordon SP, Zhang R. The association between ambient fine particulate air pollution and physical activity: a cohort study of university students living in Beijing. Int $J$ Behav Nutr Phys Act. 2017; $14: 136$

40. Yu H, Cheng J, Gordon SP, An R, Yu M, Chen X, et al. Impact of Air Pollution on Sedentary Behavior: A Cohort Study of Freshmen at a University in Beijing, China. Int J Environ Res Public Health. 2018;15:2811. 41. Kim M-G, Lee S-J, Park D, Kim C, Lee K, Hwang J. Relationship between the actual fine dust concentration and media exposure that influenced the changes in outdoor activity behavior in South Korea. Sci Rep. 2020;10:12006.

42. Noonan DS. Smoggy with a Chance of Altruism: The Effects of Ozone Alerts on Outdoor Recreation and Driving in Atlanta: Effects of Ozone Alerts. Policy Stud J. 2014;42:122-45.

43. Saberian S, Heyes A, Rivers N. Alerts work! Air quality warnings and cycling. Resour Energy Econ. 2017;49:165-85.

44. Ward ALS, Beatty TKM. Who Responds to Air Quality Alerts? Environ Resour Econ. 2016;65:487511.

45. Zhao P, Li S, Li P, Liu J, Long K. How does air pollution influence cycling behaviour? Evidence from Beijing. Transp Res Part Transp Environ. 2018;63:826-38.

46. Xia T, Nitschke M, Zhang $Y$, Shah $P$, Crabb S, Hansen A. Traffic-related air pollution and health cobenefits of alternative transport in Adelaide, South Australia. Environ Int. 2015;74:281-90.

47. Sá TH de, Tainio M, Goodman A, Edwards P, Haines A, Gouveia N, et al. Health impact modelling of different travel patterns on physical activity, air pollution and road injuries for São Paulo, Brazil. Environ Int. 2017;108:22-31.

48. Rojas-Rueda D, de Nazelle A, Teixidó O, Nieuwenhuijsen MJ. Replacing car trips by increasing bike and public transport in the greater Barcelona metropolitan area: A health impact assessment study. Environ Int. 2012;49:100-9.

49. Kosatsky T, Dufresne J, Richard L, Renouf A, Giannetti N, Bourbeau J, et al. Heat Awareness and Response among Montreal Residents with Chronic Cardiac and Pulmonary Disease. Can J Public Health Rev Can Santé Publique. 2009;100:237-40.

50. Heaney AK, Carrión D, Burkart K, Lesk C, Jack D. Climate Change and Physical Activity: Estimated Impacts of Ambient Temperatures on Bikeshare Usage in New York City. Environ Health Perspect. 2019;127:37002.

51. Chan NW, Wichman CJ. Climate Change and Recreation: Evidence from North American Cycling. :60.

52. Al-Mohannadi AS, Farooq A, Burnett A, Van Der Walt M, Al-Kuwari MG. Impact of Climatic Conditions on Physical Activity: A 2-Year Cohort Study in the Arabian Gulf Region. J Phys Act Health. 2016;13:92937.

53. Grundstein A, Elguindi N, Cooper E, Ferrara M. Exceedance of wet bulb globe temperature safety thresholds in sports under a warming climate. Clim Res. 2013;58:183-91.

54. Wadud Z. Cycling in a changed climate. J Transp Geogr. 2014;35:12-20.

55. Böcker L, Prillwitz J, Dijst M. Climate change impacts on mode choices and travelled distances: a comparison of present with 2050 weather conditions for the Randstad Holland. J Transp Geogr. 2013;28:176-85.

56. Karner A, Hondula DM, Vanos JK. Heat exposure during non-motorized travel: Implications for 
transportation policy under climate change. J Transp Health. 2015;2:451-9.

57. Chapman R, Howden-Chapman P, Keall M, Witten $\mathrm{K}$, Abrahamse W, Woodward A, et al. Increasing active travel: aims, methods and baseline measures of a quasi-experimental study. BMC Public Health. 2014; $14: 935$.

58. Keall MD, Shaw C, Chapman R, HowdenChapman P. Reductions in carbon dioxide emissions from an intervention to promote cycling and walking: A case study from New Zealand. Transp Res Part Transp Environ. 2018;65:687-96.

59. Brand C, Goodman A, Ogilvie D, Bull F, Cooper A, Day $A$, et al. Evaluating the impacts of new walking and cycling infrastructure on carbon dioxide emissions from motorized travel: A controlled longitudinal study. Appl Energy. 2014;128:284-95.

60. Goodman A, Sahlqvist S, Ogilvie D, on behalf of the iConnect Consortium. New Walking and Cycling Routes and Increased Physical Activity: One- and 2Year Findings From the UK iConnect Study. Am J Public Health. 2014;104:e38-46.

61. Mrkajic V, Vukelic D, Mihajlov A. Reduction of CO 2 emission and non-environmental co-benefits of bicycle infrastructure provision: the case of the University of Novi Sad, Serbia. Renew Sustain Energy Rev. 2015;49:232-42.

62. Zhang Y, Mi Z. Environmental benefits of bike sharing: A big data-based analysis. Appl Energy. 2018;220:296-301.

63. Winslott Hiselius L, Svensson A.. E-bike use in Sweden - CO2 effects due to modal change and municipal promotion strategies. J Clean Prod. 2017;141:818-24.

64. Quam V, Rocklöv J, Quam M, Lucas R. Assessing Greenhouse Gas Emissions and Health Co-Benefits: A Structured Review of Lifestyle-Related Climate Change Mitigation Strategies. Int J Environ Res Public Health. 2017;14:468.

65. Bucher D, Buffat R, Froemelt A, Raubal M. Energy and greenhouse gas emission reduction potentials resulting from different commuter electric bicycle adoption scenarios in Switzerland. Renew Sustain Energy Rev. 2019;114.

66. Maizlish N, Woodcock J, Co S, Ostro B, Fanai A, Fairley D. Health Cobenefits and TransportationRelated Reductions in Greenhouse Gas Emissions in the San Francisco Bay Area. Am J Public Health. 2013;103:703-9.

67. Rojas-Rueda D, de Nazelle A, Andersen ZJ, Braun-Fahrländer $\mathrm{C}$, Bruha J, Bruhova-Foltynova $\mathrm{H}$, et al. Health Impacts of Active Transportation in Europe. Ebi KL, editor. PLOS ONE. 2016;11:e0149990.

68. Creutzig F, Mühlhoff R, Römer J. Decarbonizing urban transport in European cities: Four cases show possibly high co-benefits. Environ Res Lett. 2012;7.
69. Mizdrak A, Cobiac LJ, Cleghorn CL, Woodward A, Blakely T. Fuelling walking and cycling: human powered locomotion is associated with non-negligible greenhouse gas emissions. Sci Rep. 2020;10:9196.

70. Wicker P. The carbon footprint of active sport participants. Sport Manag Rev Elsevier Sci. 2019;22:513-26.

71. Wicker P. The carbon footprint of active sport tourists: an empirical analysis of skiers and boarders.

J Sport Tour. 2018;22:151-71.

72. Chard C, Mallen C. Examining the linkages between automobile use and carbon impacts of community-based ice hockey. Sport Manag Rev. 2012;15:476-84.

73. Bunds KS, Kanters MA, Venditti RA, Rajagopalan $\mathrm{N}$, Casper JM, Carlton TA. Organized youth sports and commuting behavior: The environmental impact of decentralized community sport facilities. Transp Res Part Transp Environ. 2018;65:387-95.

74. Tóffano Pereira RP, Filimonau V, Ribeiro GM. Score a goal for climate: Assessing the carbon footprint of travel patterns of the English Premier League clubs. J Clean Prod. 2019;227:167-177.

75. Dolf $M$, Teehan P. Reducing the carbon footprint of spectator and team travel at the University of British Columbia's varsity sports events. Sport Manag Rev. 2015;18:244-55.

76. Arsenault J, Talbot J, Boustani L, Gonzalès R, Manaugh $\mathrm{K}$. The environmental footprint of academic and student mobility in a large research-oriented university. Environ Res Lett. 2019;14:095001.

77. Mourao P. Smoking Gentlemen-How Formula One Has Controlled CO2 Emissions. Sustainability. 2018;10:1841.

78. Bell SA, Choi H, Langa KM, Iwashyna TJ. Health Risk Behaviors after Disaster Exposure Among Older Adults. Prehospital Disaster Med. 2019;34:95-7.

79. Lai BS, La Greca AM, Llabre MM. Children's sedentary activity after hurricane exposure. Psychol Trauma Theory Res Pract Policy. 2014;6:280-9.

80. Tabrizi JS, Farahbakhsh M, Sadeghi-Bazargani H, Abdolahi HM, Nikniaz Z, Farhangi MA, et al. Health Consequences of Lake Urmia in Crisis in the Disaster Area: A Pilot Study. Disaster Med Public Health Prep. 2019;1-7.

81. Doubleday A, Choe Y, Miles S, Errett NA. Daily Bicycle and Pedestrian Activity as an Indicator of Disaster Recovery: A Hurricane Harvey Case Study. Int J Environ Res Public Health. 2019;16.

82. Abad RPB, Schwanen T, Fillone AM. Commuting behavior adaptation to flooding: An analysis of transit users' choices in Metro Manila. Travel Behav Soc. 2020;18:46-57.

83. Inoue Y, Havard CT. Sport and disaster relief: a content analysis. Disaster Prev Manag Int $\mathrm{J}$. 2015;24:355-68. 
84. Orr M, Inoue Y. Sport versus climate: Introducing the climate vulnerability of sport organizations framework. Sport Manag Rev. 2019;22:452-463.

85. Wicker P, Filo K, Cuskelly G. Organizational Resilience of Community Sport Clubs Impacted by Natural Disasters. J Sport Manag. 2013;27:510-25.

86. Filo K, Cuskelly G, Wicker P. Resource utilisation and power relations of community sport clubs in the aftermath of natural disasters. Sport Manag Rev Elsevier Sci. 2015;18:555-69.

87. Kirkpatrick SB. Disaster relief trials: perceptions of a disaster-themed bicycling event. Disaster Prev Manag Int J. 2019;28:386-400.

88. Kirkpatrick SJB. Pedaling disaster: citizen bicyclists in disaster response-Innovative solution or unnecessary effort? Nat Hazards. 2018;90:365-89.

89. Akiyama T, Gregorio ER, Kobayashi J. Youth sports activity and young people's well-being after a disaster: a trial with the Mastery Approach to Coaching (MAC) in the Philippines. BMC Res Notes. 2018;11:747.

90. Carson RL. Introducing the Lifetime Exercise and Physical Activity Service-Learning (LE PAS) Program. J Phys Educ Recreat Dance. 2008;79:18-35.

91. Wahl-Alexander Z, Sinelnikov OA. Using Physical Activity for Emotional Recovery After a Natural Disaster. J Phys Educ Recreat Dance. 2013;84:23-28. 92. Hong T, Farley TA. Urban residents' priorities for neighborhood features. A survey of New Orleans residents after Hurricane Katrina. Am J Prev Med. 2008;34:353-6.

93. Rolfe DT, Moiseichik ML. The Role of Parks and Recreation in Tornado Response: A Qualitative Exploration. : 9.

94. Scott D, Steiger R, Rutty M, Johnson P. The future of the Olympic Winter Games in an era of climate change. Curr Issues Tour. 2015;18:913-30.

95. Scott $D$, Steiger R, Rutty M, Fang Y. The changing geography of the Winter Olympic and Paralympic Games in a warmer world. Curr Issues Tour. 2019;22:1301-11.

96. Smith KR, Woodward A, Lemke B, Otto M, Chang CJ, Mance AA, et al. The last Summer Olympics? Climate change, health, and work outdoors. Lancet Lond Engl. 2016;388:642-4.

97. Askew AE, Bowker JM. Impacts of Climate Change on Outdoor Recreation Participation: Outlook to 2060. J Park Recreat Adm. 2018;36:97-120.

98. Brammer JR, Samson J, Humphries MM. Declining availability of outdoor skating in Canada. Nat Clim Change. 2015;5:2-4.

99. Robertson C, McLeman R, Lawrence H. Winters too warm to skate? Citizen-science reported variability in availability of outdoor skating in Canada: Variability in outdoor skating. Can Geogr Géographe Can. 2015;59:383-90.
100. Dickau M, Matthews D, Guertin É, Seto D. Projections of declining outdoor skating availability in Montreal due to global warming. Environ Res Commun. 2020;2:051001.

101. Orr M. On the potential impacts of climate change on baseball and cross-country skiing. Manag Sport Leis. 2020;25:307-20.

102. Bjørnarå HB, Torstveit MK, Stea TH, Bere E. Is there such a thing as sustainable physical activity? Scand J Med Sci Sports. 2017;27:366-72.

103. Bjørnarå HB, Torstveit MK, Bere E. Healthy and sustainable diet and physical activity: the rationale for and experiences from developing a combined summary score. Scand J Public Health. 2019;47:58391.

104. Malchrowicz-Mośko E, Płoszaj K, Firek W. Citius, Altius, Fortius vs. Slow Sport: A New Era of Sustainable Sport. Int J Environ Res Public Health. 2018;15:2414.

105. van Vuuren DP, Edmonds J, Kainuma M, Riahi K, Thomson A, Hibbard $\mathrm{K}$, et al. The representative concentration pathways: an overview. Clim Change. 2011;109:5-31.

106. Gorman M, Jones S, Turner J. Older People, Mobility and Transport in Low- and Middle-Income Countries: A Review of the Research. Sustainability. 2019;11:6157.

107. Toivanen T, Lummaa K, Majava A, Järvensivu $P$, Lähde V, Vaden T, et al. The many Anthropocenes: A transdisciplinary challenge for the Anthropocene research. Anthr Rev. 2017;4:183-98.

108. Atoui S, Chevance G, Romain AJ, Kingsbury C, Lachance, Bernard P. Daily associations between sleep and physical activity: A systematic review and meta-analysis. Sleep Med Rev. 2020;

109. Obradovich N, Rahwan I. Risk of a feedback loop between climatic warming and human mobility. J R Soc Interface. 2019;16:20190058.

110. Edgar A. Sport and Climate Change. Sport Ethics Philos. 2020;14:1-3.

111. Hamilton defends environmental posts. BBC Sport [Internet]. [cited 2020 Oct 28]; Available from: https://www.bbc.co.uk/sport/formula1/50176037

112. Miller T. Greenwashed sports and environmental activism: Formula 1 and FIFA $\$$. Environ Commun. 2016;10:719-733.

113. Breivik G. What would a deep ecological sport look like? The example of Arne Naess. J Philos Sport. 2019;46:63-81.

114. Gadais T. Sport for Development and Peace: Current Perspectives of Research. Sports Sci Hum Health - Differ Approaches [Internet]. IntechOpen; $2019 . \quad$ Available from: https://www.intechopen.com/online-first/sport-fordevelopment-and-peace-current-perspectives-ofresearch 
115. Nations U. Sport and the sustainable development goals. 2017.

116. Richter D, Matuschka FR. Differential Risk for Lyme Disease along Hiking Trail, Germany. Emerg Infect Dis. 2011;1704:1706.

117. Dingle G. Sport, the natural environment, and sustainability. Handb Sport Manag. SAGE; 2016.

118. Matthews HD, Graham TL, Keverian S, Lamontagne C, Seto D, Smith TJ. National contributions to observed global warming. Environ Res Lett. 2014;9:014010.

119. Miller T. Greenwashing Sport. Routledge; 2017. 


\section{Table}

Table 1. Summary of the results for each section separately.

\begin{tabular}{|c|c|}
\hline Sections & \\
\hline $\begin{array}{l}\text { 2. Extreme } \\
\text { weather } \\
\text { conditions }\end{array}$ & $\begin{array}{l}\text { Empirical investigations found a non-linear association between temperatures (alone or in combination with other factors such as } \\
\text { humidity) and leisure time physical activity and active transport. Higher temperature is usually associated with an increase in } \\
\text { physical activity until a certain threshold is reached, which then, triggers a sharp decrease in physical activity. Scenario-based } \\
\text { studies anticipate a positive effect of temperature increase on physical activity in at least some areas in the northern hemisphere } \\
\text { and during colder months of the year. Higher occurrence of precipitation could counteract these positive effects. One study warns } \\
\text { against increasing risks of hyperthermia during physical activity in the future. }\end{array}$ \\
\hline $\begin{array}{l}\text { 3. Greer } \\
\text { gas emi }\end{array}$ & $\begin{array}{l}\text { lied in experimental, observational and scenario-based } \\
\text { gnitude of the effect varies, active transport is mainly }\end{array}$ \\
\hline $\begin{array}{l}\text { 4. Carbon } \\
\text { footprint }\end{array}$ & $\begin{array}{l}\text { mateur and professional sport practices are associated with elevated carbon footprints for participants. Emissions vary } \\
\text { ling on the sport. However, they are primary related to transportation required for sport practices (flying or driving). For } \\
\text { Irs, carpooling and the use of fuel-efficient cars for sport-related travel might be associated with small to moderate } \\
\text { ses of their carbon footprint. }\end{array}$ \\
\hline $\begin{array}{l}\text { 6. Fut } \\
\text { physic }\end{array}$ & $\begin{array}{l}\text { Studies using simulations have proposed different scenarios in regard to future professional sport events (Olympic games) and } \\
\text { amateur sports practices (mostly in North America). Results from this literature are difficult to interpret at this stage and more } \\
\text { research is needed. It is likely that winter sports will be impacted due to shorter and less intense winter seasons; in summer, heat- } \\
\text { related issues might become increasingly important depending on the geographical locations. Other studies have proposed to } \\
\text { redefine the concepts of physical activity and sport considering climate change and the environmental effects of those practices } \\
\text { ("sustainable physical activity" and "slow sport"). }\end{array}$ \\
\hline
\end{tabular}




\section{Figures}

Figure 1. Study selection flow chart

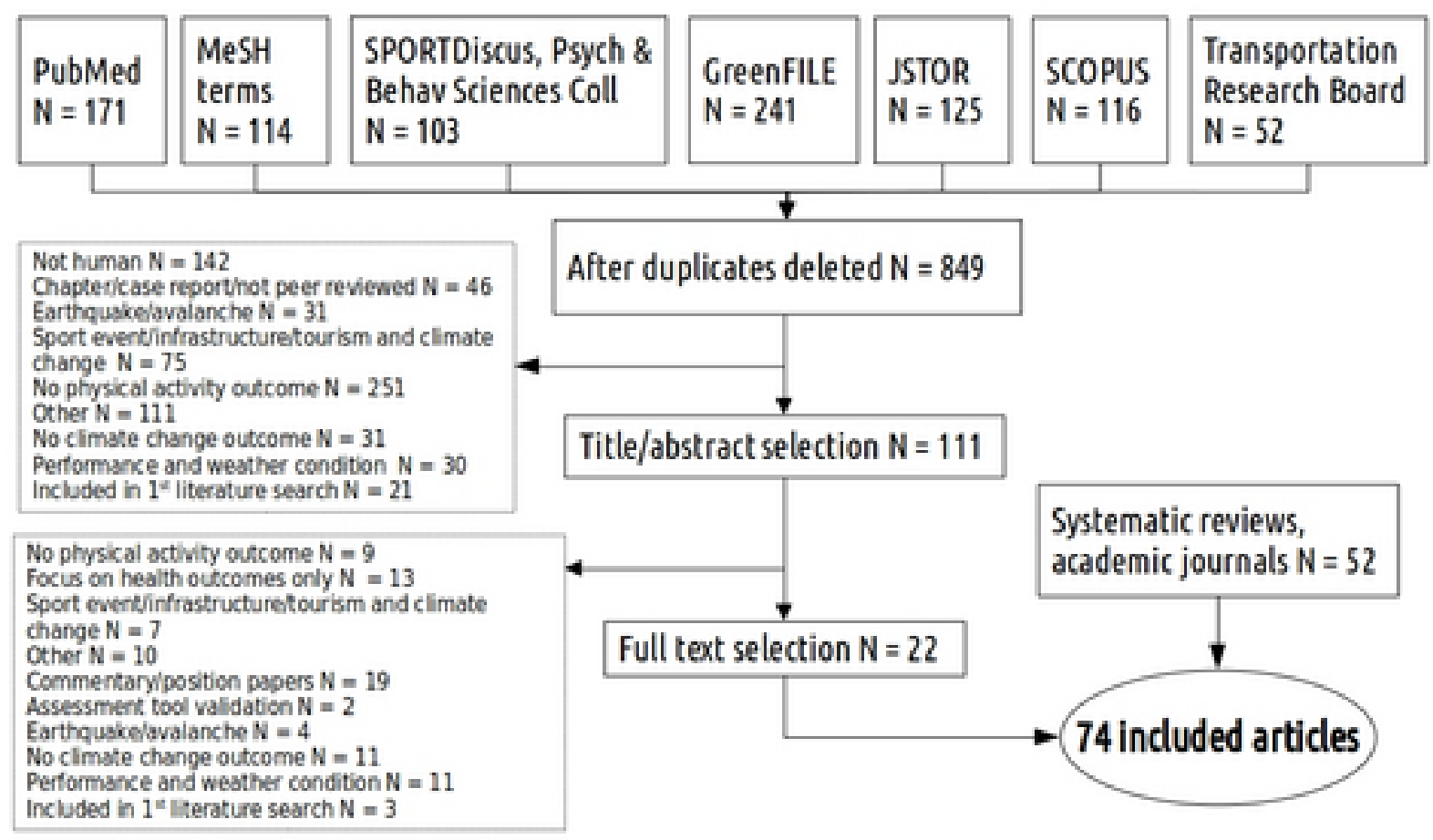


Figure 2. Geographical location of studies on climate change, physical activity behaviors and sport practices

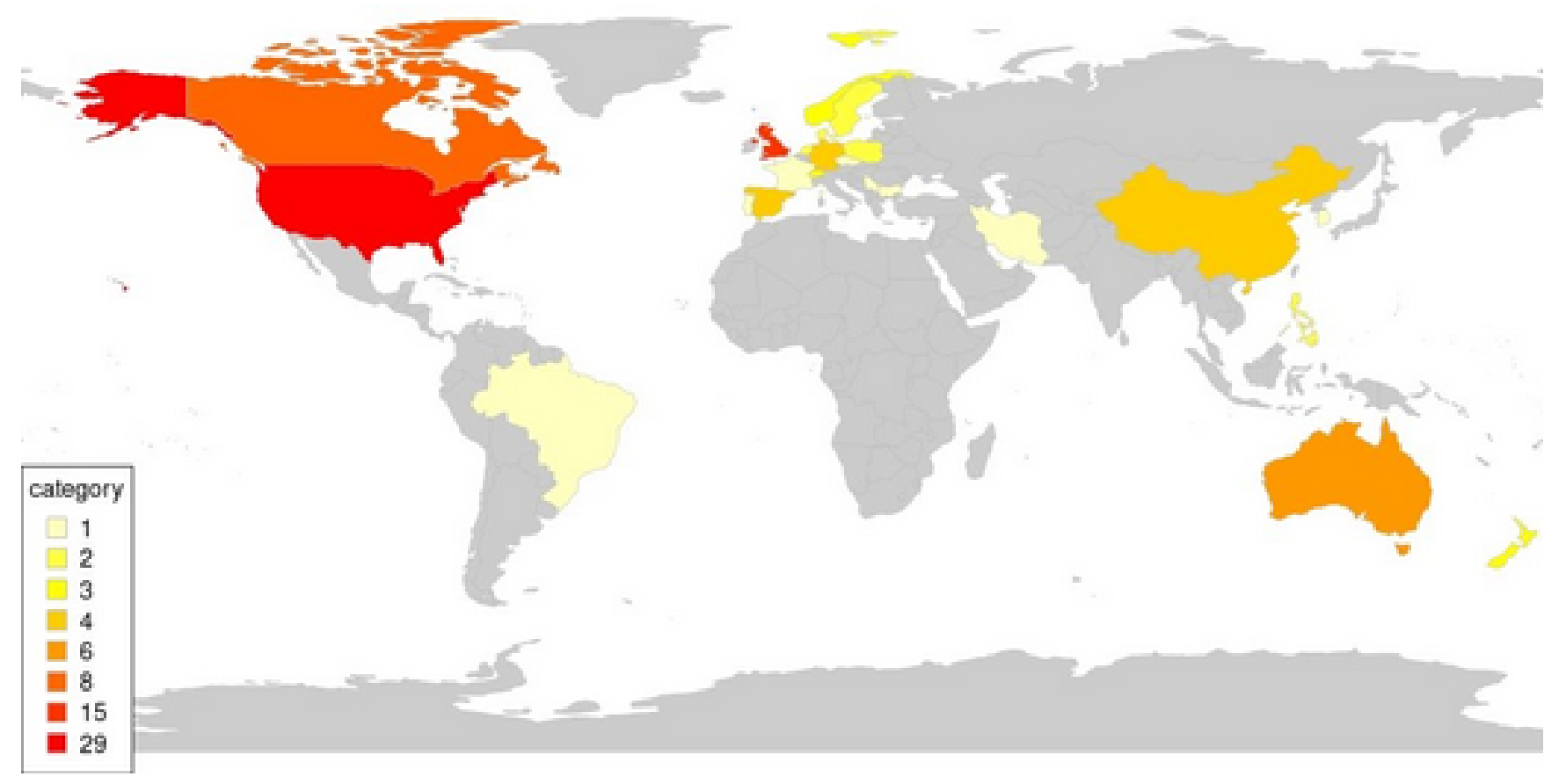


Figure 3. Framework of associations between climate change and physical activity behaviors

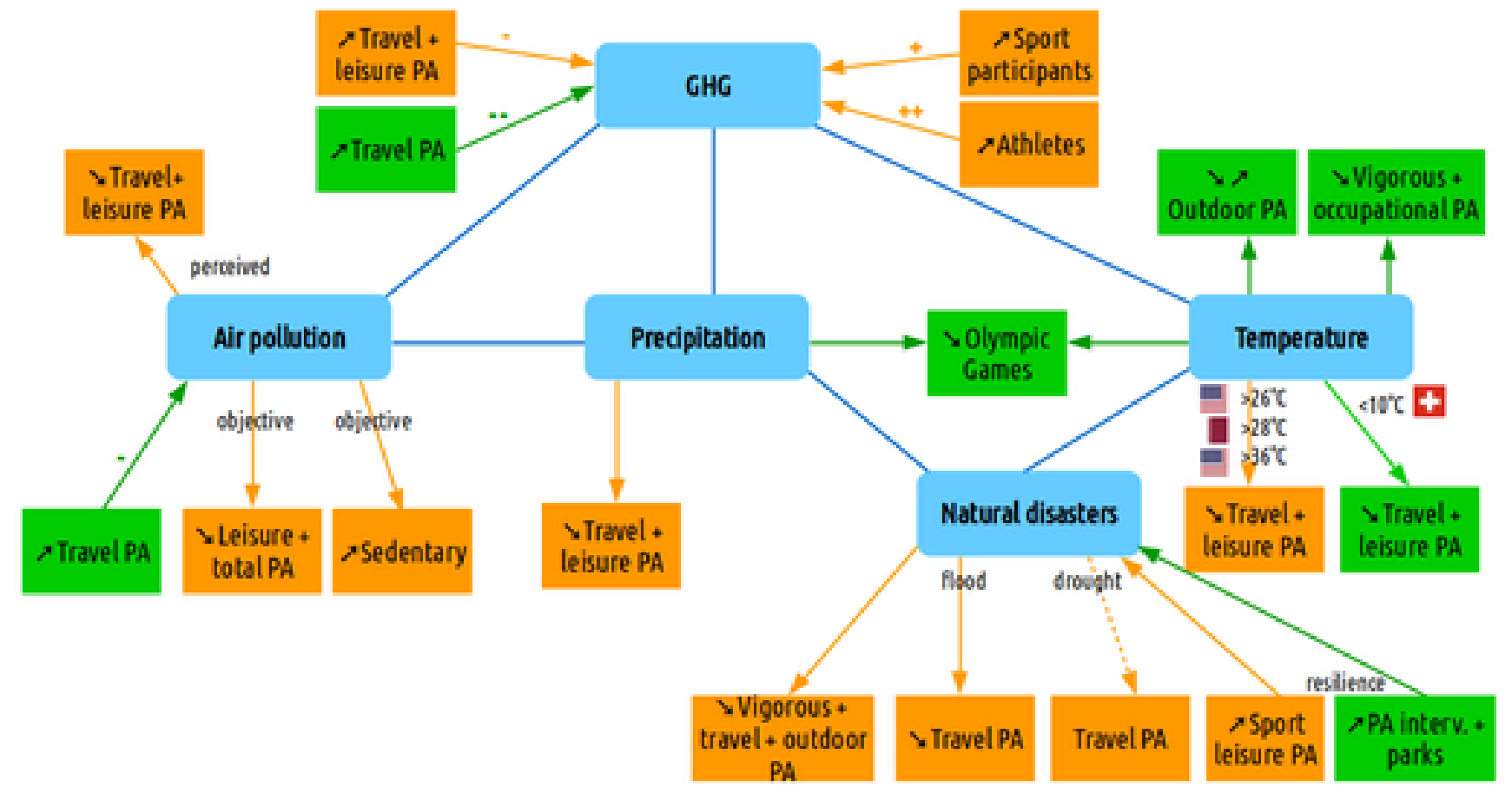

Notes. Green boxes $=$ associations based on computerized simulations, Orange boxes $=$ associations based on empirical data, $\mathrm{PA}=$ physical activity, $\mathrm{GHG}=$ greenhouse gas emissions, Arrow dash $=$ no significant association, - = negative association, -- = more negative association, + = positive association, ++ = more positive association, $\searrow \nearrow$ geographical/seasonal variations, interv. = intervention. Active travel frequency decreased for different temperature thresholds in US, Qatar and Switzerland (see flags). 


\section{Electronic Supplementary Material Appendix S1}

\section{Declarations}

\section{Data availability statement}

Research protocol and data files (.bib) are available in the following OSF account: https://osf.io/z2us6.

\section{Authors' contributions}

PB conceived the study. Data collection and extraction were performed by PB, CK and GC. All authors contributed to refinement of the study protocol, and edited, revised and approved the final version of the manuscript.

\section{Compliance with Ethical Standards}

\section{Funding}

This research received no specific grant from any funding agency. PB is supported by the Université du Québec à Montréal, Institut Universitaire de Santé Mentale de Montréal and by a salary award from the Fonds de recherche du Québec - Santé. KD and AB hold a Chercheur-Boursier Junior 1 FRQS scholarship.

\section{Conflict of Interest}

Paquito Bernard, Guillaume Chevance, Celia Kingsbury, Aurélie Baillot, Ahmed-Jérôme Romain, Virginie Molinier, Tegwen Gadais and Kelsey Dancause declare that they have no conflicts of interest relevant to the content of this review.

\section{Acknowledgments:}

The authors would like to thank Philippe Squarzoni, Pablo Servigne, Jean-Marc Jancovici, Philippe Bihouix, and members of Thinkerview for their seminal work 


\author{
Appendix S1. Search strategies \\ Search Terms for PubMed: \\ Mesh terms \\ (("Exercise"[Mesh] OR "Sports"[Mesh]) AND (("Climate Change"[Mesh]) OR "Natural \\ Disasters"[Mesh])) \\ Free words \\ (("physical exercise"[Title/Abstract]) OR $\quad$ ("physical activity"[Title/Abstract]) OR

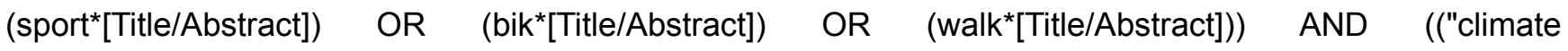 \\ change"[Title/Abstract]) OR (greenhouse[Title/Abstract]) OR ("natural disaster"[Title/Abstract]) OR \\ $\begin{array}{llllll}\text { ("extreme weather"[Title/Abstract]) } & \text { OR } & \text { (hurricane[Title/Abstract]) } & \text { OR } & \text { (flood[Title/Abstract]) } & \text { OR }\end{array}$ \\ (drought[Title/Abstract])) \\ Search Term for SPORTDISCUS \\ "natural disaster" OR "climate change" OR "greenhouse"' AND "physical activity" OR sport \\ Search Term for GREEN FILE \\ "physical activity" OR sport OR walk OR biking AND "climate change" OR greenhouse OR "natural \\ disaster" \\ Search Term for Transportation Research Board \\ ("climate change" OR "natural disasters" "greenhouse") AND ("bike" OR "sport" OR "walk" OR "active \\ transport" OR "physical activity")

\section{Search Term for Scopus} \\ ABS ("climate change") OR ABS ("natural disasters") OR ABS (greenhouse ) AND ( ABS ( "physical \\ activity") OR ABS ("sport") OR ABS (walk) OR ABS (bike ) OR ABS ("active transport") ) AND \\ NOT INDEX (medline) AND NOT ( SUBJAREA (agri OR bioc OR immu OR neur OR phar)) AND \\ NOT ( SUBJAREA ( eart OR ener OR engi OR envi)) AND ( LIMIT-TO ( DOCTYPE, "ar")) AND \\ ( LIMIT-TO ( LANGUAGE , "English") ) \\ Search Term for JSTOR \\ ((("climate change") OR ("natural disaster") OR (greenhouse))) AND ab:("sport") OR ab:("physical activity") \\ OR ab:("active transport")
}

Bernard P et al. (2021). Climate change, physical activity and sport: a systematic review. Sports Medicine, https://doi.org/10.1007/s40279$\underline{021-01439-4}$ 